\title{
PERIPECIA DUN TURCO APRESADO POLA MARIÑA DE GUERRA A MEDIADOS DO SÉCULO XVIII
}

\author{
por \\ ANTONIO RODRÍGUEZ FRAIZ
}

Non fai moitos anos unha embarcación de mais que mediano porte achábase amarrada ós peiraos que a Mariña de Guerra do Estado Español garda no Ferrol. Unha noite a nao - Greenpeace-e os seus servidores, cortadas as amarras, deixando a babor e estribor os castelos de Santa María da Palma e San Felipe, adentráronse nas coruscantes e infindas augas de Atlántico.

Douscentos corenta anos denantes - 1752 - uns probes turcos ou mouros, como eran tidos, nin siquera nome tiñan. "... de la nacion Turca, que por avanzada de Marina se reclutaron a esttos dominios, quienes para su consistencia, lo hacen con cadena al pie y sin emvargo de ello aora de proxsimo uno de ellos tubo el axselo de hacer fuga que dio motivo ha salir Condutta en su busca, la que le dio caza, a la Circunferencia de la Villa de Ribadeo"'.

Mouro este sin nome e encadeado, como soía adoitarse e tratada a esclavitude en xeral e ó negro en particular. A primeira consideración que se facía nos clásicos e en xeral na sociedade esclavista do século XVII, lóxicamente era a carencia total de perspectivas liberadoras dos que se achaban sometidos a este status vivencial. No auto sacramental "Pedro Telonario" de Mira de Amescua, a esclavitude é tratada de "segunda morte" e o esclavo por non ter, nin siquera tiña un nome permanente, dependendo do amo acasional...

\footnotetext{
' Protocolo orixinal no Arq. do Concello de Ares. Coruña.
} 
- Esclavo. ¿Como es tu nombre?

- Pedro fué cuando era mio, $\mathrm{y}$ ahora que tuyo soy

Seré el nombre que quieras...

O Turco ou Mouro que nos ocupa tampouco o tiña, como asi o amosa o documento e proceso que motiva iste traballo.

Tivo millor sorte o famoso "Moro Alí" de Pontevedra. Di a pauliña publicada por orden do Arcebispo Don Pedro Carrillo e Acuña o 11 de Febreiro do ano 1656, por desexar: "...os herdeiros do Licdo. Pedro Vazquez, Rector que fue de Marcón, que le tuvo como en deposito... quieren venderle suponiendo que era suyo...". Parece que non era así, senon que o tal Alí había sido comprado nos grandes mercados esclavistas existentes, sobre todo nos portos marítimos da Península para rescatar a un veciño de Pontevedra, Fabian Vázquez. Esta pauliña, descuberta por P. Pérez Constanti no Arquivo do Concello de Pontevedra, é tan significativa que o ilustre investigador dí: "...que muchos (despachos) han pasado por sus manos pero ninguno tan 'curioso'; por la causa que lo produjo como este"2.

O problema do Mouro Alí, na Pontevedra de mediados do século XVII, foi intensamente vivido, pasando a memoria histórica do pobo e ó acerbo cultural e artístico do mismo. A fornida e barroca figura do Atlante, sosten do púlpito de pedra da igrexa de Santa María de Mourente, din ser representación do devandito "Moro Alí".

Se a pauliña que fixo saber: "...a todos los hombres, mujeres, moços, moças, clerigos, legos y otras personas de qualquier estado que sean vecinos, estantes y avitantes de las feligresías de San Bartolomé de la Villa de Pontevedra, Santa María la Mayor y en las demas de este Arçobispado: "...para que o Mouro Alí fose presentado e entregado polos herdeiros do Crego Pedro Vázquez de Marcón, para ser trocado polo Fabián Vázquez, e non o facian, motivóu tan curioso documento: non o é menos o feito polo escrivan do Ferrol, no bélido lugar do Baño de Mugardos, Simon Sánchez de Andrade, a petición dos mais outos Xefes do Departamento da Mariña de Guerra do Ferrol, no 1752.

Según se desprende do protocolo devandito. O Teniente de Bernarda na Real Armada da Sua Maxestade e direitor nas reales fábricas dos Castelos de San Martiño, Palma e a Redonda, na entrada da Ría do Ferrol, Don Pedro Serrano que ademais era encargado dos traballos do arranque

\footnotetext{
${ }^{2}$ P. Pérez Constanti: Notas Viejas Galicianas, pxs. 139 e segts.
} 
da pedra nas canteiras da Redonda - Concello da Vila de Mugardospara as obras que se estaban a facer nos Arsenáis do Ferrol e Asteleiros do Esteiro, a conta da Real Facenda.

Con tan importante persoaxe, tamén comparece un probe labrador veciño de San Vicente de Meá - Mugardos-Pedro Bizoso, como suposto cómplice na fuxida de un dos turcos: "...que por avanzada de Marina se reclutaron a esttos dominios, que en el para su ensistencia, lo hacen con cadena al pie y sin embargo de ello, aora de proximo uno de ellos tubo el axselo de hacer fuga, que dio motivo a salir Condutta en su busca, la que le dio caza, a la Circunferencia de la Villa de Ribadeo, de donde fué conducido a dha. Real Fabrica y por aversele echo cargo de luego, a luego sobre el modo de haber sacado la cadena, que tenia en el pie, con que hizo la fuga, significó, averle protexido para ello un sujeto que no conocia siquiera ynmediato ha aquel destino, aunque no sabia su bicindario, ni lugar, y como al transito se le estrechase a la axsignacion sin mas conocimiento; que el de su boluntariedad para exsimirse de el condigno castigo a que era acreedor, transitando por dicho lugar de Rilo y Casa del expresado Bizoso, a cuya ynmediacion susiste de pie fixo un piquete del Rexmto. de Vitoria, para conttener los ympulsos de las deserciones sin hazerse con recurso de que, para la que hizo promediar desde su destino ha aquel lugar (de Rilo-San Vicente de Meá) aunque sea por rutta derecha, muchos mas, como es el de O Baño, Mugardos, Jesteyra, Casares, Seara y otros, y aun mas tomando su paso a por la parte del Bendaval que por ser de noche y aquel disttrito algo mas expeso para su alvergue y recoximiento se allan otros disttintos lugares, bien entendido, que aun con dificultad compareza, ni aun ejecutoria pronunciativa, axsigno a dcho. Bizoso, si que le parecía que en aquel sitio avia sacado la cadena, y que en el mesmo, y para dcho. fin lo protexiera un hombre, que alli avia allado, y no asientta si era vecino o transitante, como ni tampoco el sitio efecttivo, lo que no podia hacer, por no ser practico del pays y su desercion a la ora de la noche. Echo cierto de quererla cubrir con una apariencia ympura...".

O feito foi que o Comandante Xeral da Mariña do Departamento do Ferrol, Don Cosme Álvarez de los Rios, mandóu encadear no Castelo da Palma o probe labrego, Pedro Bizoso, inda que logo, por ser tempo de sementeira do centeo e o trigo: "...o prenottado Bizoso dando fianza de estar a derecho Juzgado e Setenciado en dcha. causa, y que de echo, se le de soltura, y se retire a su casa para la culttura de su hacienda, por ser el tiempo obportuno de la siembra y labrador de primera cañama de aquella fra. y cumpliendo con este echo dixo, se obligava y obligó con su persona $\mathrm{y}$ vienes muebles y rrayces presentes y futuros de que sinenvargo de su 
ygnocencia en quanto por el Moro, por este particular se le quiere prohixar por exsimirse del delito que ha cometido y estará delante de dcho. Don Pedro Serrano: de su SSria. el Sr. Comandante General y en otros qualesquiera tribns. donde condusga a derecho...".

Foi fiador de Pedro Bizoso o seu sogro, Antonio Rey, tamen campesiño de Meá. Sigue o interesante documento probatorio de que si a piratería turca no Mediterráneo foi un feito que fixo xurdir diversas Ordes relixiosas para a liberación dos cautivos cristiáns, como foi a compra do Mouro Alí de Pontevedra; tamén foi exercida en non pequena escala, nada menos que pola Real Armada da España do Imperio, sobor dos turcos ou mouros que podian atrapar, para ser encadeados nas canteiras da Redonda, bélido lugar do promontorio de Santa Catalina de Montefaro, nos concellos de Ares e Mugardos. Un dos xigantes que gardan a Ría do Ferrol.

Neste ano cumplense seiscentos anos da fundación polo cabeleiro Fernán Perez de Andrade O Bó, do convento da Terceira Orden dos franciscáns, moimental e artistica edificación monástica convertido logo en Cuartel de Artillería, hoxe case que desguarnecido e sin interés militar algún; polo que o Ministerio do Exército debe devolvelo para que poida ser utilizado en pleno rendimento mais acorde cos desexos dos fundadores e proteitores ${ }^{3}$.

Sobrancean neste antergo cenobio as artísticas arcadas do ano da fundación, según costa no moimental escudo dos Andrade fundadores, por certo que en lingua galega: "ESTE M(oesteiro) FEZO FERNAN P(ere)S DANDRADE, ANNO D(omi)NI MCCCXCII", da Sáa Capitular, para a que, na adaptación os servicios militares do mosteiro, o escritor Adolfo Torrado debuxóu bélidos motivos: o claustro renacentista e a torre barroca en forma de balconada, sobor das rias do Ferrol, Ares e Coruña. Diante un coidado xardín con pezas procedentes de edificación do 1392, para ledicia dos amantes da natureza e arte que cheguen a aquel remanso de paz e beleza.

Arte, historia e armonía, patrimonio dos libres. Non o foron para o turco ou Mouro encadeado, con outros compañeiros, nas canteiras da Redonda que, para acadar a libertade non dibidóu de atravesar vales e montes irtios, de mar a mar, para ser atrapado na anterga vila das Ribeiras do Eo, para ser novamente encadeado.

Con él o bó campesiño de Meá, tamén de por vida xunguido a terra, Pedro Bizoso, cristianamente rompedor das cadeas dun probe Mouro, sin nome.

\footnotetext{
${ }^{3}$ A. Felpedo García: Un Centenario que nos atañe... Rev. Semana Santa.
} 


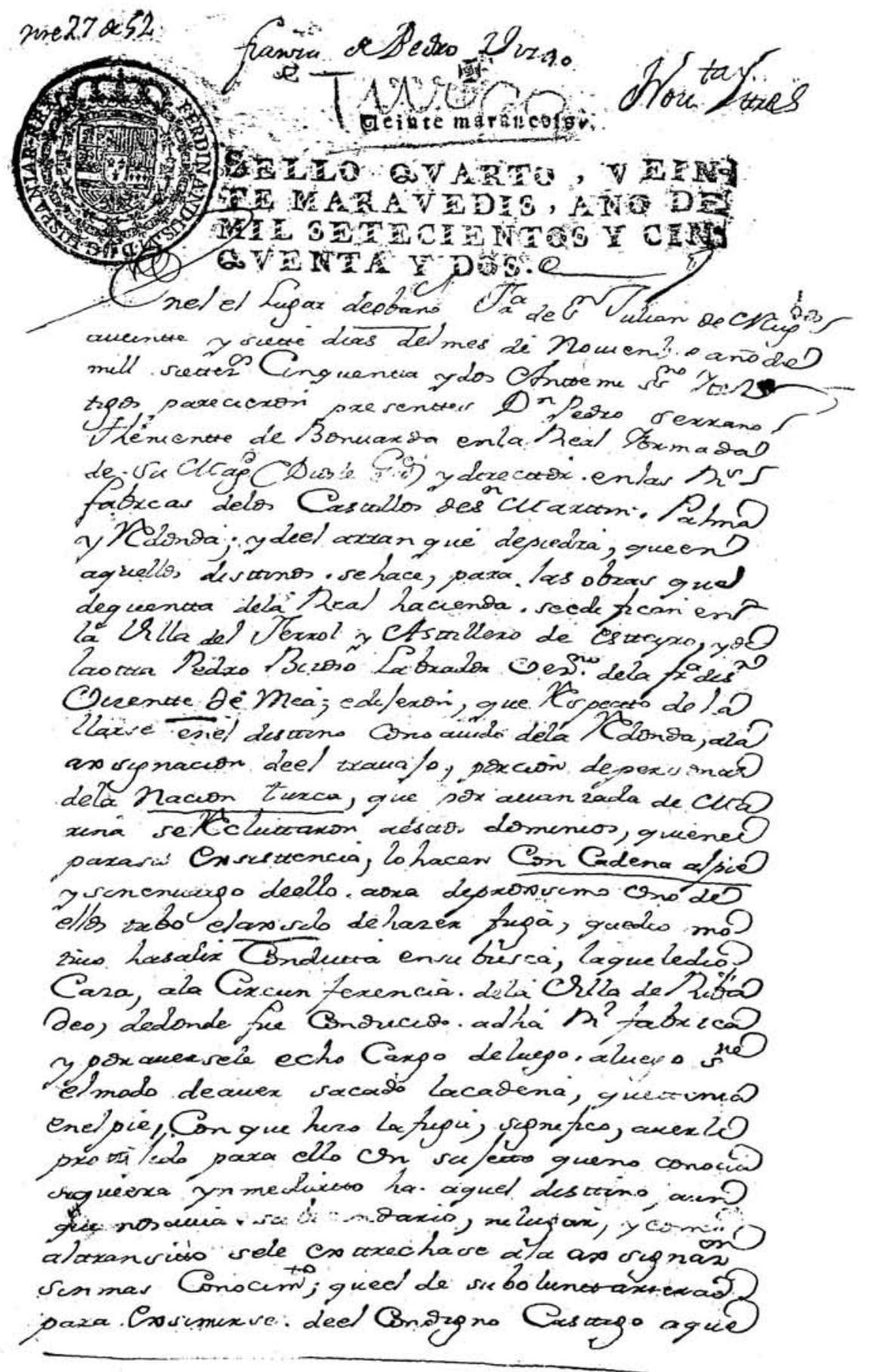




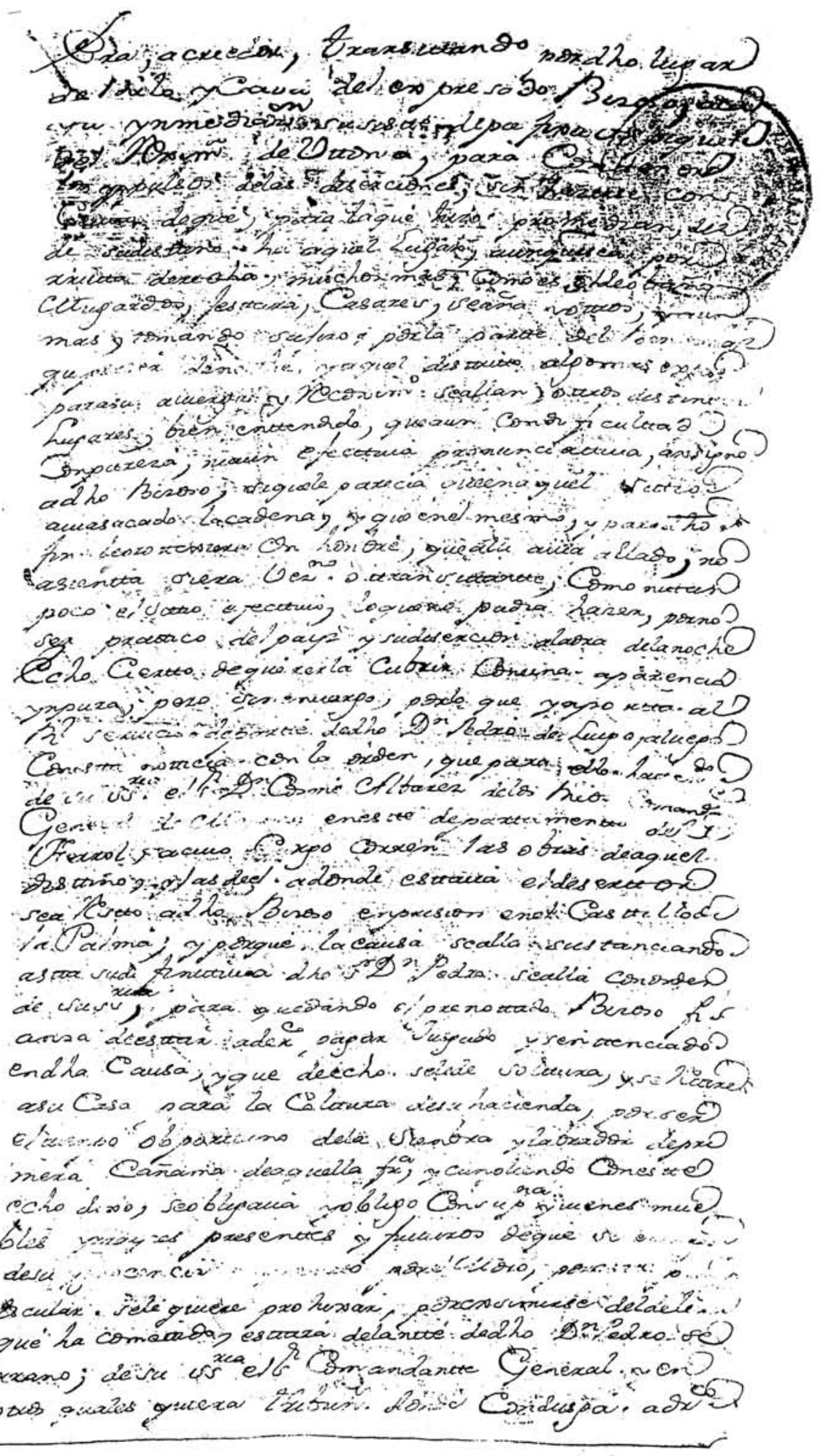

(c) Consejo Superior de Investigaciones Científicas 


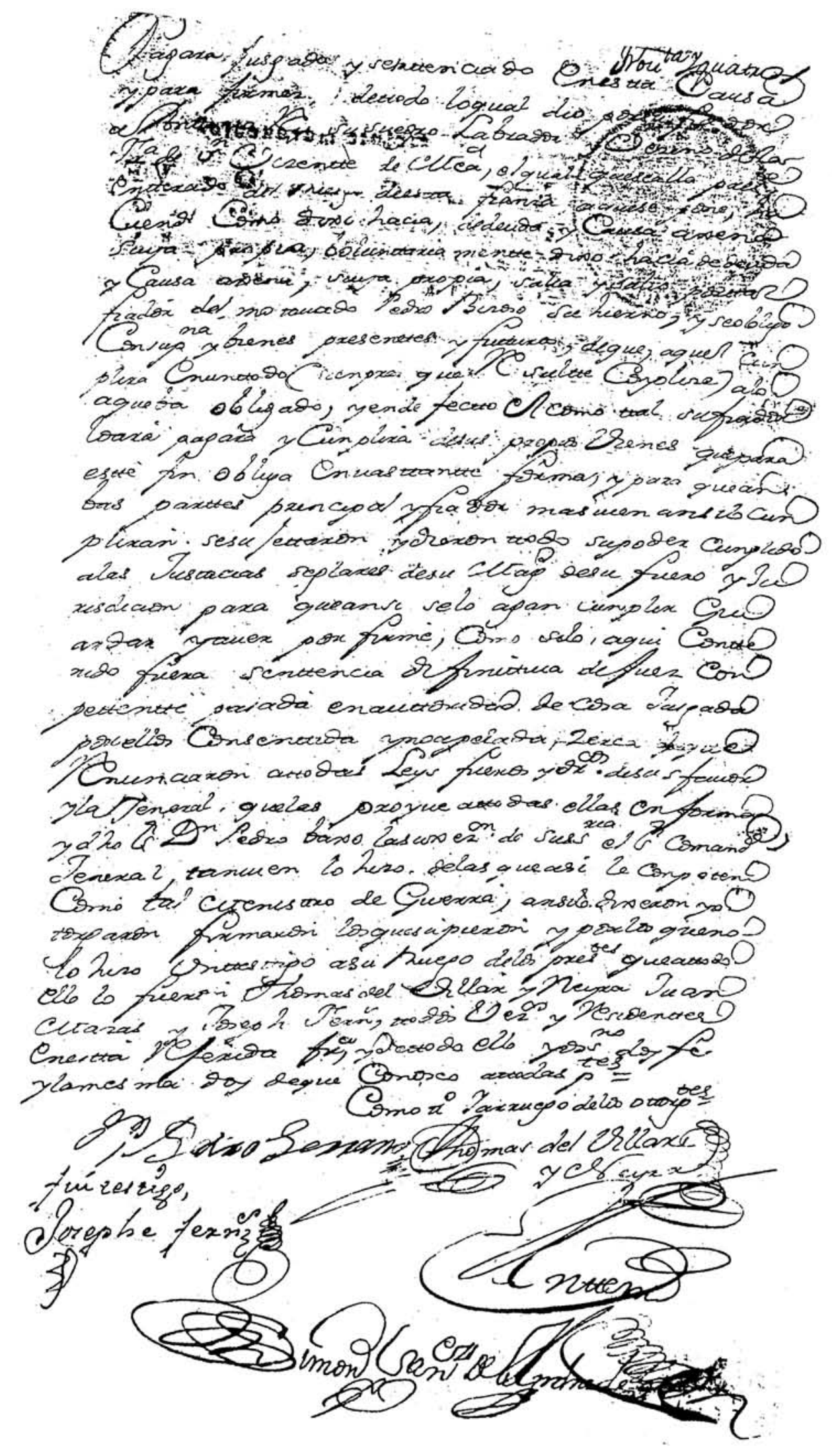

(c) Consejo Superior de Investigaciones Científicas

http://estudiosgallegos.revistas.csic.es Licencia Creative Commons 3.0 España (by-nc) 


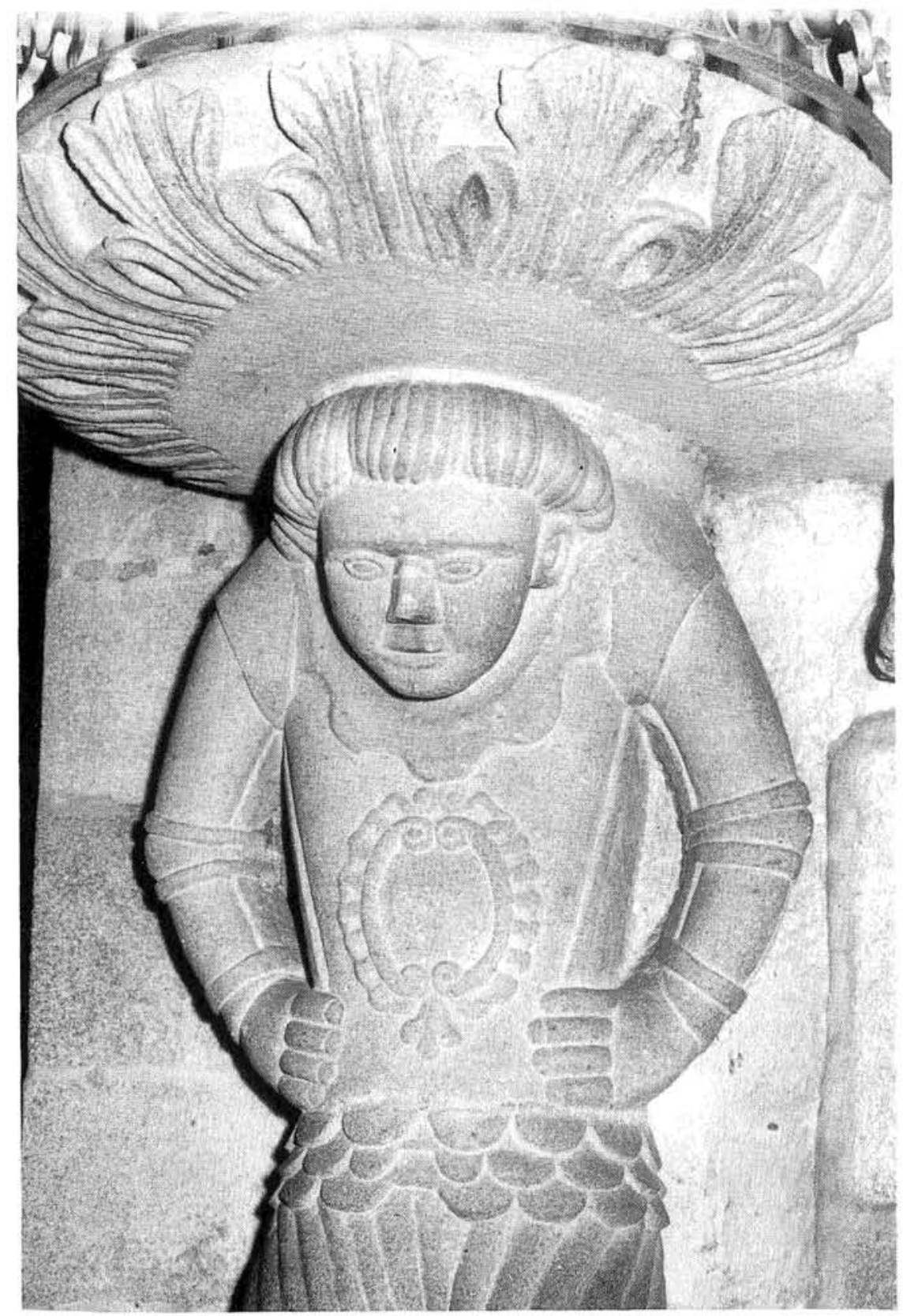

Atlante do púlpito de Santa María de Mourente (Pontevedra). Fegura do mouro "Alí", según a xente. 